\title{
PENATALAKSANAAN ARTHRITIS RHEUMATOID PADA LANJUT USIA DI PANTI SOSIAL TRESNA WERDHA BUDI LUHUR JAMBI
}

\author{
Ariyanto $^{1)}$, Tina Yuli Fatmawati ${ }^{2)}$ \\ ${ }^{1,2}$ Prodi DIII Keperawatan, STIKes Baiturrahim Jambi \\ Email:riyan_909@yahoo.co.id
}

\begin{abstract}
Rheumatoid arthritis is a chronic systemic inflammatory disease that attacks several joints, the synovium, which occurs in the inflammatory process that causes damage to the joints. The problem faced by partners is that most elderly people still do not understand rheumatism management properly such as a healthy diet, the importance of maintaining body weight to avoid obesity and have not understood traditional rheumatoid management with lemongrass therapy. This community service activity has been conducted at the Tresna Werdha Social Institution in Jambi City in December 2018. The method used a survey, lecture, discussion, demonstration / simulation approach. The results achieved are the implementation of health counseling in the elderly about rheumatoid management, demonstration of lemongrass therapy therapy and conducting pain scale measurements before and after therapy.
\end{abstract}

Keywords: Rheumatoid arthritis; Lamongrass therapy

\begin{abstract}
ABSTRAK
Artrhitis rheumatoid /rematik merupakan penyakit inflamasi sistemik kronis yang menyerang beberapa sendi, sinovium, yang terjadi pada proses peradangan yang menyebabkan kerusakan pada tulang sendi. Permasalahan yang dihadapi mitra adalah Sebagian besar lansia masih belum memahami penatalaksanaan rematik dengan benar seperti diet yang sehat, pentingnya menjaga berat badan agar terhindar dari kegemukan dan belum memahami penatalaksanaan rematik secara tradisional dengan terapi serai. Kegiatan Pengabdian masyarakat ini telah dilaksanakan di Panti Sosial Tresna werdha Kota Jambi pada bulan Desember 2018. Metode pengabdian menggunakan pendekatan survei, ceramah, diskusi, demonstrasi/simulasi. Hasil yang dicapai adalah terlaksananya Penyuluhan kesehatan pada lansia tentang penatalaksanaan rematik, demonstrasi terapi kompres serai dan melakulakan pengukuran skala nyeri sebelum dan sesudah dilakukan terapi.
\end{abstract}

Kata Kunci: Penatalaksanaan Rematik, Terapi serai

\section{PENDAHULUAN}

Artrhitis rheumatoid /rematik merupakan penyakit inflamasi sistemik kronis yang menyerang beberapa sendi, sinovium, yang terjadi pada proses peradangan yang menyebabkan kerusakan pada tulang sendi (Khitchen 2011). Angka kejadian rematik pada tahun 2008 yang dilaporkan oleh Organisasi Kesehatan Dunia WHO adalah mencapai 20\% dari penduduk dunia yang telah terserang rematik, dimana 5-10\% adalah mereka yang berusia 5-20 tahun dan 20\% adalah mereka yang berusia 55 tahun. Rematik ini lebih sering terjadi pada perempuan dan biasanya menyerang orang yang berusia lebih dari 40 tahun (Arif Muttaqin, 2008).

Nyeri sendi merupakan keluhan utama yang sering dirasakan setiap penderita rematik, jika rematik sampai menyerang bagian syaraf, nyeri sendi dapat menjalar 
jauh hingga keseluruh tubuh, hal ini akan berakibat pada penurunan aktifitas Lansia. Salah satu pengobatan tradisional untuk mengurangi nyeri adalah dengan kompres hangat serai. Serai adalah salah satu tanaman yang memiliki zat sebagai penghangat, anti radang dan dapat memperlancarkan aliran darah. Serai mengandung minyak atsiri yang memiliki efek tersebut (Wijayakusuma, 2007).

Data lansia di Panti Tresna Werda Budi Luhur Provinsi Jambi bahwa penyakit terbanyak adalah Rematik disusul Hipertensi dan penyakit lain seperti Stroke, Gastritis, Insomnia, Gout artritis, Diabetes melllitus, Asma, Anemia, Herpes, Alzhemer, Dermatitis dan LBP( Low Back Pain). Dari wawancara dengan petugas belum pernah dilakukan penyuluhan penanggulangan nyeri secara nonfarmokologi pada penderita artritis rheumatoid ( Data Panti , 2018). Oleh karena itu lansia harus lebih memahami pentingnya penatalaksanaan lansia baik secara medis maupun cara tradisional serta bagaimana cara pencegahan sehingga dapat mengurangi terjadinya serangan nyeri / kambuh ulang.

Permasalahan yang dihadapi oleh mitra antara lain: Sebagian lansia belum memahami penatalaksanaan rematik dengan benar seperti diet yang sehat, pentingnya olahraga, pentingnya menjaga berat badan agar terhindar dari kegemukan. Sebagian Lansia belum memahami penatalaksanaan rematik secara tradisional dengan terapi serai.

Dari uraian diatas maka kami tertarik untuk melakukan kegiatan pengabdian masyarakat dengan judul "PKM Penatalaksanaan Arthritis Rheumatoid Pada Lanjut Usia Di Panti Sosial Tresna Werdha Budi Luhur Jambi”.

\section{TARGET DAN LUARAN}

1. Target
Target yang harus di dapat dalam kegiatan pengabdian kepada masyarakat ini adalah:

a. Lansia memahami tentang penatalaksanaan rematik dengan ramuan tradisional (> 95\%)

b. Lansia dapat mendemonstrasikan terapi serai $(>95 \%)$.

2. Luaran

Luaran kegiatan pengabdian ini selain publikasil pada jurnal adalah:
a. Pemahaman Lansia penatalaksanaan rematik.
b. Penerapan / Demonstrasi terapi serai

\section{METODE PELAKSANAAN}

Kegiatan Pengabdian kepada masyarakat ini telah dilaksanakan pada bulan Desember 2018 dengan dibantu oleh beberapa mahasiswa STIKes Baiturrahim dengan sasaran Lansia di Panti Sosial Tresna werdha Budi Luhur Jambi, Khususnya yang menderita Rematik .

Tahapan kegiatan pengabdian kepada masyarakat meliputi :

Persiapan

1. Pertemuan dengan Kepala dan Petugas Panti.

2. Mengidentifikasi masalah

3. Perumusan solusi : Menyampaikan rencana kegiatan kepada pihak panti.

Pelaksanaan

1. Melakukan pretest (menggali pemahaman lansia tentang Rematik).

2. Memberikan pendidikan kesehatan /penyuluhan tentang Penatalaksanaan Rematik

3. Demonstrasi Terapi dengan kompres Serai

4. Melakukan Terapi Serai pada Lansia (sebelum dan sesudah terapi diukur skala Nyeri)

Monitoring dan Evaluasi

\section{HASIL DAN PEMBAHASAN}

Kegiatan pengabdian masyarakat di Panti Werdha telah dilaksanakan sesuai 
dengan rencana yang disusun. Kegiatan Penyuluhan dilaksanakan kepada warga khususnya lansia yang menderita rematik di Panti Sosial Tresna Werdha. Kegiatan ini dibantu oleh mahasiswa/i program studi D3 Keperawatan. Tujuan dari Kegiatan penyuluhan ini agar warga panti memahami tentang tentang penatalaksanaan rematik khususnya bagaimana cara membuat ramuan tradisional dengan terapi kompres serai . Pada kegiatan demonstrasi terapi serai sebelumnya dilakukan pengukuran skala nyeri (pretest) dan sesudah terapi dilakukan test pengukuran skala nyeri (posttest).

Kompres serai merupakan pengobatan tradisional atau terapi alternatif untuk mengurangi nyeri arthritis rhematoid. Serai adalah salah satu tanaman yang memiliki zat sebagai penghangat, anti radang dan dapat memperlancarkan aliran darah. Serai mengandung minyak atsiri yang memiliki efek tersebut (Wijayakusuma, 2007).

Berikut ini hasil pengukuran skala nyeri sebelum dan setelah dilakukan terapi kompres serai:

Tabel.1 Hasil pengukuran skala nyeri sebelum dan setelah dilakukan terapi serai

\begin{tabular}{cccc}
\hline $\begin{array}{c}\text { NO } \\
\text { PESERTA }\end{array}$ & $\begin{array}{c}\text { UMUR } \\
(\text { TH })\end{array}$ & $\begin{array}{c}\text { SKALA } \\
\text { NYERI } \\
\text { PRE }\end{array}$ & $\begin{array}{c}\text { SKALA } \\
\text { NYERI } \\
\text { POST }\end{array}$ \\
\hline 1 & 85 & 6 & 4 \\
2 & 66 & 5 & 4 \\
3 & 69 & 8 & 6 \\
4 & 62 & 6 & 4 \\
5 & 72 & 7 & 5 \\
6 & 68 & 6 & 4 \\
\hline
\end{tabular}

Tabel diatas diperoleh hasil dari 6 Peserta terdapat perubahan skala nyeri dari Berat menjadi sedang (1 orang), skala nyeri sedang menjadi berkurang ( 5 orang).

Evaluasi dari program kegiatan pengabdian kepada masyarakat dipanti dilaksanakan dimulai dari persiapan /perencanaan, pelaksanaan/proses dan evaluasi hasil.

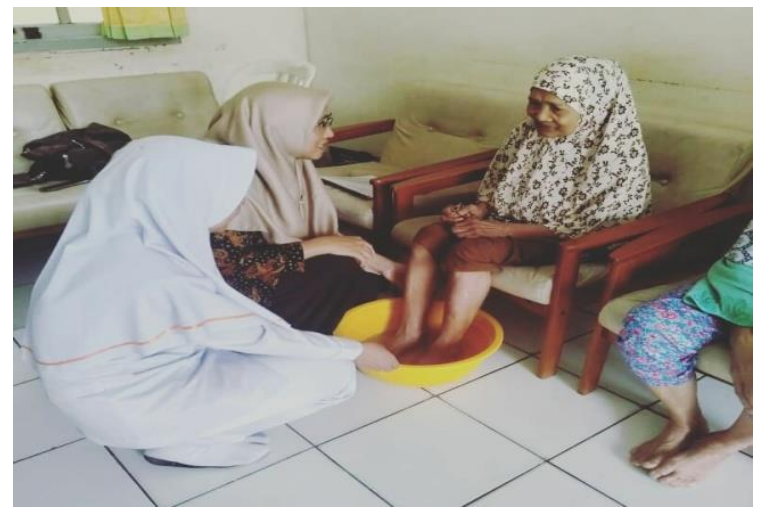

Gambar1. Demonstrasi terapi rendam serai

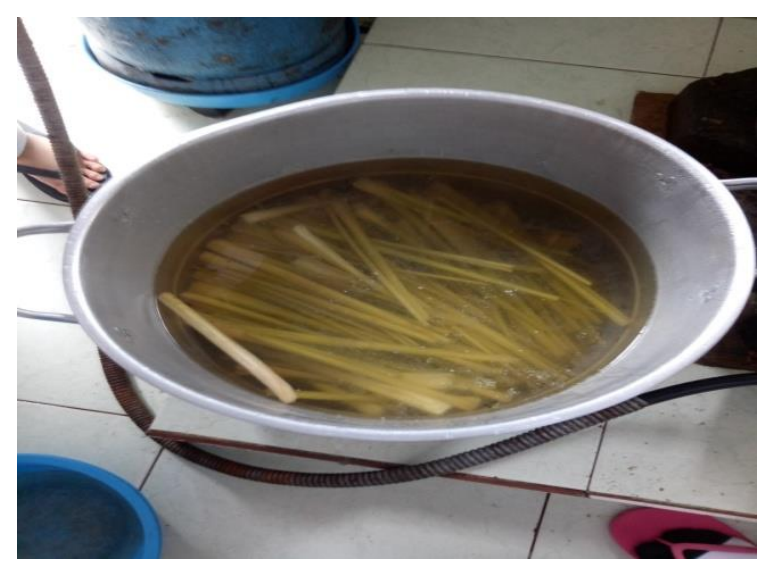

Gambar 1. Rebusan Serai

\section{KESIMPULAN DAN SARAN}

\section{Kesimpulan}

Mayoritas penderita rematik mampu memahami tatalaksana rematik seperti diet rematik, pencegahan kegemukan dan pengobatan tradisonal. Sebagian besar Lansia dapat memahami bagaimana cara membuat ramuan tradisional dengan terapi kompres hangat serai.

\section{Saran}

Kepada petugas panti agar dapat meningkatkan kesehatan lansia melalui kegiatan pendidikan kesehatan sehingga lansia dapat menjaga pola hidup sehat terhindar dari berbagai penyakit.

\section{UCAPAN TERIMAKASIH}

Ucapan terimakasih di sampaikan kepada Sekolah Tinggi Ilmu Kesehatan 
Baiturrahim yang telah menfasilitasi kegiatan ini , dan tak lupa kepada Kepala Kepala Panti dan semua pihak yang telah membantu kegiatan Pengabdian kepada Masarakat ini.

\section{DAFTAR PUSTAKA}

Depkes RI, 2010, Pedoman Umum Pengembangan Desa dan Kelurahan Siaga Aktif. Jakarta : Pusat Promosi Kesehatan Sekretaris Jenderal Kementerian Kesehatan RI

Darmojo,B.R, dan Martono.H. 2010. Buku Ajar Geriatri. Balai Penerbit FKUI. Jakarta.

Dalimartha, S. 2008. Herbal Untuk Pengobatan Reumatik. Penebar Swadaya. Jakarta.

Khitchen. 2011. Kapita Selekta Kedokteran. Media Aesculaapius FKUI. Jakarta.

Padila. 2013. Buku Ajar Keperawatan Gerontik. Nuha Medika. Yogyakarta.

PSTW Budi Luhur Jambi. (2018). Jumlah Lansia beserta Penyakit di Panti Sosial Tresna Werdha Budi Luhur Jambi Tahun 2015-2018. PSTW Budi luhur Jambi. Jambi. 